American J. of Engineering and Applied Sciences 2 (4): 735-742, 2009

ISSN 1941-7020

(C) 2009 Science Publications

\title{
The Impact of Companies' Age on Safety Culture in the Metal Products Industry
}

\author{
${ }^{1}$ Maryam Ooshaksaraie, ${ }^{2}$ Amran Ab. Majid, ${ }^{2}$ Muhammad Samudi Yasir and ${ }^{2}$ Redzuwan Yahaya \\ ${ }^{1}$ Department of Business Administration, Islamic Azad University-Tonekabon Branch, Iran \\ ${ }^{2}$ Faculty of Science and Technology, University Kebangsaan Malaysia, \\ 43600 Bangi, Selangor, Malaysia
}

\begin{abstract}
Problem statement: Safety culture is a complex structure in an organization that includes values and attitudes, most of which are potentially changeable and related to actual accident behavior. In this study, the components of safety culture included organizational commitment, management involvement, employee empowerment, reporting system and rewarding system. Approach: The numbers of occupational injuries in industries have steadily increased during recent years. The major objectives of this study were to evaluate the safety culture and to analyze the difference in safety culture in the metal products industry in Iran (Guilan province) with regard to companies' age. Metal products industry was chosen because of the higher occupational injuries rates amongst the industries in Iran. Results: The companies were chosen based on their age. A total of 714 respondents from 14 companies participated in the survey. The method used in this study was a questionnaires quantitative type based on a Lickert scale and the data collected were analyzed statistically. The one-way ANOVA was used to test for significant difference in safety culture in the metal products industry with regard to companies' age. The results showed that safety culture was not strong based on the mean for average score of 2.58 which was less than 3 compared to the possible maximum of 5. One-way ANOVA analysis revealed that there was a significant difference among safety culture with respect to companies' age. New companies had stronger safety culture compared to older one. Conclusion: Based on the findings the hypothesis of this study is accepted. This study also indicated that the safety culture in the metal products industry in target population group was not strong however, can be improved through improvement of its five components.
\end{abstract}

Key words: Safety culture, organizational commitment, management involvement, employee empowerment, reporting system, rewarding system

\section{INTRODUCTION}

The rapid development of new technology has essentially changed the nature of work and has increased the complexity of systems within many of industries. Hence, the world becomes increasingly complicated. These complex systems require a tight combination between technical and human subsystems $^{[1]}$. In this sense, the failure of either subsystem can often cause a failure of the entire system. Moreover, catastrophic breakdowns of these systems create serious threats, not only for those within the organization, but also for the surrounding public. Simultaneously, the accidents that occur in workplaces have also become more complex and in some cases more frequent. In fact, with each failure that occurs, the knowledge of the factors which make organizations vulnerable to failures has grown. It has become clear that such vulnerability does not originate from just human error, technological failures, or environmental factors alone, but rather the fixed organizational policies and standards which have repeatedly been shown to predate the catastrophe. In recent years the safety practitioners have focused on the organizational values that might enhance risk and crisis management and safe performance in industries complex conditions ${ }^{[2]}$. It has become clear that such vulnerability does not originate from just human error, technological failures, or environmental factors alone. Rather, it is the fixed organizational policies and standards which have repeatedly been shown to predate the catastrophe. Therefore, safety practitioners in recent years have begun to focus on the organizational values that might enhance risk and crisis management and safe

Corresponding Author: Maryam Ooshaksaraie, No.13, 11th Street, Kooye Panzdah Khordad,

Emam Khomeini Blvrd, Postal Code: 41946-45655 Rasht, Guilan, Iran Tel: +98-9113332890 
performance in industries complex conditions. Some scholars ${ }^{[3]}$ believed that culture and technology actually go hand in hand.

In this scene, culture is said to be the very heart of organizations. It consists of attitudes, perceptions, beliefs and values, which need to be set in context. In the face of new mandates, it is believed that culture can play a vital role in helping organizations respond to the many challenges they face now. According to this study in an era of increasing competition and scarce resources, maximizing safety performance is a critical issue for managers in the organizations and industries. This study believes that strong and positive safety culture as the powerful apprentice can work in the region of constraints to produce high-quality results. Also, strong and positive safety culture can improve safety performance in the workplaces. Hence, researchers and business strategists who study the organizational culture and safety phenomenon also believe that strong safety culture in large measure initiatives drive safety performance.

In general, most industrial companies in Iran comply established occupational safety procedures and policies, but the numbers of occupational injuries in industries have steadily increased during recent years. However, most accidents and incidents in Iranian industries are a direct result of not adhering to their established safety procedures, as well as lack of strong safety culture, safe working conditions and employees' safe work attitudes and actions. Thus, the participation of all employees including managers and non-managers is vital in policymaking, establishing and implementing a feedback system that drives continuously toward safety improvement in industrial companies to achieve a successful safety program. It must be mentioned that safety culture has an important role in reducing occupational accidents in industry. The current situation of safety in the metal products industry shows that there was room for improvement of safety by the management in the implementation the safety procedures. Currently, no studies have been conducted on safety culture in the metal products industry in Iran (Guilan province). Therefore, the main objective of this study was to evaluate the current safety culture in this industry based on the perception of employees. Furthermore, this study examined the difference in safety culture in the metal products industry in Iran (Guilan province).

Safety culture: A safety culture exists within an organization where each individual employee, regardless of their position, accepts and assumes an active role in error prevention and that role is supported by the organization. In fact, safety culture is a set of guidelines' beliefs that by which group of individuals guided in their behavior by their joint belief in the importance of safety and their shared understanding that every member willingly upholds the group's safety norms and will support other members to that common end. Fuller and Vassie ${ }^{[4]}$ revealed that safety culture as an important phrase and concept came to prominence following a number of major accidents in the late 1980s. According to Wiegmann et al. ${ }^{[1]}$, the current interest in the term safety culture can be traced directly back to the Chernobyl accident in 1986. They mentioned that conceptualizations and definitions of safety culture have been derived mainly from the more general notion of organizational culture. Hence, some of the most important definitions of safety culture in recent studies argued followed by the definition of safety culture, which used in this study.

Wiegmann et al. ${ }^{[5]}$ argued that safety culture is defined as a set of beliefs, norms, attitudes, roles and social and technical practices that are concerned with minimizing the exposure of employees, managers and members of the public to conditions considered dangerous or injurious. However, Wiegmann et al. ${ }^{[1,5]}$, believe that by considering commonalties among the various definitions of safety culture; a global definition can be formulated. They argued that safety culture is the enduring value and priority placed on worker and public safety by everyone in every group at every level of an organization. According to Cooper ${ }^{[6]}$ safety culture is what emerges as a result of a concerted organizational effort to move all cultural elements towards the objective of safety, including an organization's members, its systems and work activities. Clarke ${ }^{[7]}$ defines safety culture as the core assumptions and beliefs that organizational members hold concerning safety issues. Dingsdag et al. ${ }^{[8]}$ termed safety culture such as a very useful way of understanding how organizations influence the safety behavior of their employees. From this behavior, employees learn what actions will be rewarded, tolerated or punished. This in turn influences what actions and behavior employees initiate and maintain, which directly relates to safety performance. Harvey et $a l .{ }^{[9]}$ reported that safety culture of an organization is the product of individual and group values, attitudes, perceptions, competencies and patterns of behavior that determine the commitment to and the style and proficiency of, a safety management and organization's health. Finally, from the standpoint of this study, safety culture refers to a complex structure that includes values and attitudes, most of which are potentially changeable and relate to actual accident behavior. Also, 
safety culture refers to the extent to which individuals and groups will commit to personal responsibility for safety, act to preserve, enhance and communicate safety concerns, strive to actively learn, adapt and modify both individual and organizational behavior based on lessons learned from mistakes and be rewarded in a manner consistent with these values. Therefore, safety culture is assumed to be a component of an organization that can be improved rather than simply instilled. Obviously, such a distinction is important when it comes to both measuring and changing safety culture within organizations.

The literature of organizational safety supports the inclusion of several aspects of an organization to describe the components of safety culture. Studies have indicated that safety culture is best considered as a multidimensional concept. Few studies ${ }^{[10]}$ have been designed to capture multiple components of safety culture as it has been defined in the literature. Harvey et $a l .{ }^{[9]}$ believed that the attempts to define components, which constitute a good safety culture, all imply that effective provision for safety depends as much upon organizational culture generally as it does upon specific attention to safety matters. Wiegmann et al. ${ }^{[11]}$ also, argued that there has been no consensus on the exact number of components that reflect organizations' safety culture.

Apart from those arguments, the most current components of safety culture in terms of this study introduced in five major components that are such as (i) organizational commitment, which is a subset of organizational factors, denoting the extent to which upper level management demonstrates positive and supportive safety values, attitudes and behaviors ${ }^{[8,12-22]}$, (ii) management involvement that is contingent on management's physical approach to safety ${ }^{[19]}$. For instance, direct involvement of upper and middle level management, in safety meetings and workshops or in safety oversight ${ }^{[23]}$. It also, refers to the extent to which both upper and middle level managers get personally involved in critical safety activities within the company, (iii) employee empowerment pertains to the responsibility placed on employees by upper level management and the degree to which that responsibility authorizes or motivates employees to have safe behavior. Short et al. ${ }^{[23]}$ stated that in a general sense employee empowerment refers to the extent of employees' ability to perform their functions accurately. Studies ${ }^{[1,24]}$, reported that employee empowerment within the context of safety culture means that employees have a substantial voice in safety decisions, have the leverage to initiate and achieve safety improvements, whole departments to be accountable for their actions and take pride in the safety record of their company, (iv) reporting systems that can prevent many of occupational accidents, which can not be compensated. The free and uninhibited reporting of safety issues that come to the attention of employees during the course of their daily activities is an important facet of an effective reporting culture. Reporting system is one of the necessary elements for successful safety management that control and support safety processes $^{[18,25,26]}$. Such system evaluates and intends in improving safety and limiting occupational accidents ${ }^{[10,23]}$. According to Wiegmann et al. ${ }^{[1]}$, effective and systematic reporting system in companies is the basis to identifying the weakness of safety management before accidents occur and (v) rewarding systems that refers to the manner in which both safe and unsafe behaviors and activities in companies are evaluated and the consistency in which rewards or penalties are doled out according to these evaluations. Hence, a fair evaluation and reward system is needed to promote safe behaviors and discourage or correct unsafe behaviors. Through reward systems, the safety culture in organizations is maintained. Behaviors that are rewarded will be repeated and safety behavior will be modified ${ }^{[27]}$.

As the safety culture is a subset of the overall organizational culture. It is one of the most stable and substantial forces within organizations, shaping the way members think, behave and approach their work. In short, it represents an organization's unique style of operation. Furthermore, positive and strong safety culture is a comprehensive set of values such as commitment of the organization, particularly senior management, to the achievement of a high standard of safety and the demonstration of this commitment through communications and maintenance, consistent management response to incidents, consistent decision making, reward and approval systems, allocation of resources training, a caring management attitude, acceptance of the participative safety controls. People need to have a better perception of what safety values and norms looks like in a practical sense in the field of industrial settings. In this sense, it is very important for industrial companies to understand importance and meaning safety culture (especially positive and strong safety culture) in their area of activities. Hence, positive and strong safety culture implies that all the people involved, share similar perceptions and adopt the same positive attitudes towards safety ${ }^{[28]}$.

Gibbons et al. ${ }^{[2]]}$ identified a set of indicators that contributed to positive and strong safety culture. Those indicators according to this study are such as (i) organizational commitment, (ii) management 
involvement, (iii) employee empowerment, (iv) report system and (v) reward system. Other scholars mentioned other components that make up an effective safety culture. Based on existed literature, important elements to the development of positive and strong safety culture are such as strategic and action plan to integrate safety that looks for integrate safety into all aspects of activities in companies. Risk control system is the second element of a basic foundation for positive and strong safety culture is the presence and quality of the industry's risk control systems. Safety management information system as the third element and foundation for positive and strong safety culture is the presence and quality of safety management information system in companies. Safety management system is the fourth important element of positive and strong safety culture that is the extent to which safety management systems in companies are reviewed. Integrated job and safety training is the fifth essential element for positive and strong safety culture that refers to the extent of high quality integrated job and safety training that every employee receives. Attitude to safety values as the sixth element of positive and strong safety culture reveals that safety culture should be well based in a company that is the existence of a good attitude to safety values among its employees. Visible indication of senior safety staff is important as the seventh element of a positive and strong safety culture. Hence, that is the position of senior safety staff in a company's organizational hierarchy that gives a visible indication of the importance emotionally involved to safety culture. Communication as the eighth element of positive and strong safety culture is the ability to effectively communicate with employees, though not an easy skill to master for managers; it is an obvious requirement for good leadership. Organizational learning as the ninth element of positive and strong safety culture is defined as a change of goal directed behavior based on experience. Continuous learning is the tenth element for a strong and positive and strong safety culture in a company, which makes safety culture as a dynamic phenomenon in work life safety ${ }^{[30,31]}$.

\section{MATERIALS AND METHODS}

A total of 14 companies in the metal products industry in Guilan province of Iran were involved in the questionnaire surveys. Out of 14, 2 companies started their activity 10 years and below (new companies), 10 companies started their activity 11-20 years (young companies) and 5 companies started their activity 21 years and above (old companies). Metal products industry was selected because of the higher occupational injuries rate amongst the industries in Iran (35.69 injuries per 1,000 workers in 2004). This study was conducted at research site within three years from 2005-2008. The population of the target group consisted of managers and non-managers. Random sampling method is used to define target population. The total sample frame consisted of 168 managers and 674 non-managers, randomly selected from distinguished companies. The high response rate of this study's survey package was as follows: out of all 168 managers, 128 completed questionnaires were returned which can result in a $76.19 \%$ response rate. Out of all 674 non-managers, 586 completed questionnaires were returned which can result in an $86.94 \%$ response rate. Hence, the sample was 714 and yielded an overall response rate of $84.80 \%$.

This study used quantitative and descriptive methodology to collect and statistically analyze data. Data collection was concluded questionnaire surveys, using a five point Likert scales. The questionnaires were designed to address the respondents' perceptions of the current safety culture of the metal products industry in Iran (Guilan province) through its five components. The safety culture questionnaire in this study was based on the development and initial validation of a safety culture survey of Wiegmann et al. ${ }^{[1]}$ standard questionnaire which was modified for the purpose of this study. The questionnaire was aimed at evaluating safety culture with consideration of the five components. They are as follows: organizational commitment, management involvement, employee empowerment, reporting system and rewarding system, with each component consisting of 7 items. Therefore, the questionnaire includes 35 items.

Gathering data for the quantitative method was done based on hypothesis on the difference in safety culture in the metal products industry in Iran (Guilan province) with regard to companies' age. Hence, in order to investigate the difference in safety culture in the metal products industry One-way ANOVA analysis was applied. The total score of safety culture components in terms of employees' perspective was analyzed and used to test the hypothesis of this study. A significant level of 0.5 (p-value) was used to establish the difference between the variables. The smaller $\mathrm{p}$ level value represents more certainty of the estimation and vice versa for a higher p-value.

Performance scores on safety culture components were calculated to evaluate the safety culture in terms of employees' perspective. Performance scores on safety culture and its five components were determined by calculating the mean of participants' responses to each item. The mean score on each of the components 
Am. J. Engg. \& Applied Sci., 2 (4): 735-742, 2009

indicates respondents' general opinion of them. If the mean score on each of the components was below 3, showing that respondents generally hold a negative point of view of their companies' safety culture in regard to each component. It is interpreted to mean that in their opinion those components were not strong. While, if the mean score on each of the components was 3 and above, showing that respondents generally hold a positive point of view of their companies' safety culture in regard to each component. It is interpreted to mean that in their opinion those components were strong. The mean score on all of the components indicates the respondents' general opinion of safety culture within companies in the metal products industry of Guilan province in Iran. If the mean score on all of the components was below 3 , indicating that respondents generally hold a negative point of view of their companies' safety culture. It is interpreted to mean that in their opinion safety culture was not strong. While, if the mean score on all of the components was 3 and above, indicating that respondents generally hold a positive point of view of their companies' safety culture. It is interpreted to mean that in their opinion safety culture was strong.

\section{RESULTS}

In this study, safety culture is analyzed in terms of respondent's point of view. Also, the safety culture situation according to the score of each component is analyzed.

Table 1 shows the results of the description for average score of safety culture and its components. The result shows that the mean for average score of safety culture was $2.58 \pm 0.58$ in the metal products industry compared to the possible maximum score of 5. Since, the mean score on safety culture was less than 3 , it shows that, safety culture was not strong in the metal products industry in Guilan province, Iran. The result shows that the mean for average score of organizational commitment, management involvement, employee empowerment, reporting system and rewarding system as the safety culture components was $2.50 \pm 0.69$, $2.53 \pm 0.85, \quad 2.61 \pm 0.71, \quad 2.44 \pm 0.75$ and $2.80 \pm 0.71$ respectively, in the metal products industry compared to the possible maximum score of 5. Since the mean score on all of the safety culture components was less than 3 , it shows that, organizational commitment, management involvement, employee empowerment, reporting system and rewarding system to safety issues was not strong in the metal products industry in Guilan province, Iran.
Table 1: Average score of safety culture and its components

\begin{tabular}{lllll}
\hline $\begin{array}{l}\text { Safety culture (components) } \\
\text { average score }\end{array}$ & $\begin{array}{l}\text { Lowest } \\
\text { obtained }\end{array}$ & $\begin{array}{l}\text { Highest } \\
\text { obtained }\end{array}$ & Mean & $\begin{array}{l}\text { Std. } \\
\text { deviation }\end{array}$ \\
\hline Safety culture & 1.00 & 4.50 & 2.58 & 0.58 \\
Organizational commitment & 1.00 & 4.40 & 2.50 & 0.69 \\
Management involvement & 1.00 & 5.00 & 2.53 & 0.85 \\
Employee empowerment & 1.00 & 4.30 & 2.61 & 0.71 \\
Reporting system & 1.00 & 4.70 & 2.44 & 0.75 \\
Rewarding system & 1.00 & 4.60 & 2.80 & 0.71 \\
\hline
\end{tabular}

Table 2: Average score of safety culture based on companies' age

\begin{tabular}{lllllc}
\hline Companies & $\begin{array}{l}\text { Safety culture } \\
\text { average score }\end{array}$ & $\begin{array}{l}\text { Lowest } \\
\text { obtained }\end{array}$ & $\begin{array}{l}\text { Highest } \\
\text { obtained }\end{array}$ & Mean & $\begin{array}{l}\text { Std. } \\
\text { deviation }\end{array}$ \\
\hline Age & New & 1.50 & 4.00 & 2.68 & 0.58 \\
& Young & 1.00 & 3.90 & 2.47 & 0.53 \\
& Old & 1.30 & 4.50 & 2.63 & 0.62 \\
& & 1.00 & 4.50 & 2.58 & 0.58 \\
\hline
\end{tabular}

Table 3: Variance analysis of difference in safety culture based on companies' age

\begin{tabular}{lcrcll}
\hline & Sum of squares & df & Mean square & F & Sig. \\
\hline Between groups & 6213.878 & 2 & 3106.939 & 7.558 & 0.001 \\
Within groups & 292275.087 & 711 & 411.076 & & \\
\hline Total & 298488.965 & 713 & & & \\
\hline
\end{tabular}

Dependent variable: Safety culture total score

The results of the description for average score of safety culture based on companies' age is shown in Table 2. The results show that the mean for average score of safety culture with regard to companies' age was $2.68 \pm 0.58,2.47 \pm 0.53$ and $2.63 \pm 0.62$ in new, young and old companies respectively, compared to the possible maximum score of 5 . As the mean score on safety culture was less than 3 , these indicate that, safety culture was not strong for any companies' age in the metal products industry in Iran (Guilan province). The overall result shows that the mean for average score of safety culture was $2.58 \pm 0.58$ in the metal products industry compared to the possible maximum score of 5 . Since, the mean score on safety culture was less than 3, it shows that, safety culture was not strong in the metal products industry in Iran (Guilan province).

In this study the results obtained are analyzed for any difference in safety culture in the metal products industry in Iran (Guilan province) regarding companies' age. The hypothesis is: There is a difference in safety culture in the metal products industry in Iran (Guilan province) regarding companies' age.

Table 3 shows the result of variance analysis for the difference in safety culture in the metal products industry with respect to companies' age. Since the Sig (p- value) is less than 0.01, there is a statistically difference in safety culture in the metal products industry at the $99 \%$ confidence level.

Table 4 shows the result of comparison of safety culture in new, young and old companies using the Duncan Post Hoc Test. This analysis shows that there is a difference in safety culture between young companies 
Table 4: Duncan post hoc test (tests of between-subjects effect) safety culture based on companies' age

\begin{tabular}{llr}
\hline & \multicolumn{2}{l}{ Subset for alpha $=0.05$} \\
Companies' age & 1 & 2 \\
\hline Young companies & 86.5771 & \\
Old companies & & 92.0160 \\
New companies & & 93.7295 \\
Sig. & 1.0000 & 0.3980 \\
\hline
\end{tabular}

compared with new and old companies. However there is no difference in safety culture between new companies compared with old companies. Since, according to Kinner and Gray ${ }^{[33]}$ there are no differences among the means in either group and any member of either group was different from a member of the other group. Furthermore, the result shows that new companies had stronger safety culture, while young companies had the weakest safety culture in the metal products industry in Iran (Guilan province).

\section{DISCUSSION}

It is noticed that safety culture and its related vital components in the metal products industry of target population group were not strong. It is interpreted to mean that employees had no strong safety values to implement their job effectively and to assess important factors in achieving the desire objectives.

Wiegmann et al. ${ }^{[1]}$ in their study assessed the safety culture within the commercial aviation industry based on five global components of safety culture which are organizational commitment, management involvement, employee empowerment, reward systems and reporting systems. The goal was to allow employees throughout the airline (from line pilot to toplevel management) to give their personal assessment of these organizational factors, taking into account the operational constraints of the airline and its personnel. The mean score for the airline on all five dimensions was above the average score, indicating that respondents hold a generally positive opinion of their airline's safety culture in regard to each dimension. Hence, the results indicated positive overall airline performance in relation to organizational safety factors. The research results of Wiegmann et al. ${ }^{[11]}$ showed that respondents evaluated organizational commitment as the strongest component and reward system as the weakest component within the commercial aviation industry. $\mathrm{Kao}^{[32]}$ in his study assessed the level of present safety culture within a petrochemical organization (five petrochemical companies) in Taiwan. Factor analysis, t-test and one-way ANOVA variance analysis were used to analyze the collected data sets and to seek a deeper understanding of the dependence of safety performance to safety culture. The study was interested in determining whether employee's background and environment variables affect differences, relation and calculation in safety culture level for different companies. The results indicated positive overall performance in relation to organizational safety culture factors.

\section{CONCLUSION}

Improving safety by improving safety culture presents a clear way forward for the different industries in Iran. Among those industries the metal products industry in Iran is the pioneer in promoting a consistent national standard to improve safety competency for key safety positions. Recognition of the need to further improve safety within the Iranian industries, especially the metal products industry will lead some companies to adopt the safety culture concept to change safety behaviors. However, the principles of safety culture are challenging to apply in practice. The metal products industry is dynamic, diverse and of critical importance to Iran's economy and people's way of life. The safety of this industry is directly linked to the safety of its employees. While industry safety is improving, it is still a long way short of best practice and many Iranian are still being injured and killed every year.

The statistical analyses demonstrated the evaluation of the present safety culture in the metal products industry in the target population group. The findings showed that from employees' perspective, safety culture was not strong in the metal products industry in Iran (Guilan province). Analysis of safety culture components revealed that all of them were evaluated as weak components and categorized in terms of obtained scores respectively are as follows: reporting system, organizational commitment, management involvement, employee empowerment and rewarding system. The result showed that the respondents evaluated rewarding system as the strongest component, while reporting system was assessed as the weakest component. It is interpreted to mean that managers used different rewards as a strategy to control safety affairs within companies, without using or creating reporting channels and system to monitor activities and functioning in work places.

The comparison in safety culture in the metal products industry identified a difference between new, young and old companies. The results showed that new companies had the strongest safety culture and young companies had the weakest safety culture in the metal products industry in Iran, Guilan province. It is 
interpreted to mean that managers of new companies in the first stage of organizational life initiate the establishment of units for their companies. They have enough motivation to provide essential facilities and to consider related functions in the production line, but during their production process and maintenance period, when confronted with some financial problem they $\mathrm{z}$ to decrease production or services costs to keep the companies afloat. Hence, the new companies have higher safety situation than the others.

\section{REFERENCES}

1. Wiegmann, D.A., H. Zhang, T.L.V. Thaden, G. Sharma and A.A. Mitchell, 2002. A synthesis of safety culture and safety climate research. Technical Report, University of Illinois ARL-02-3/FAA-02-2. http://www.humanfactors.uiuc.edu/Reports\&Paper sPDFs/TechReport/02-03.pdf

2. Gadd, S., 2002. Safety Culture: A review of the literature. Technical Report, Human Factors Group, Health and safety laboratory HSL/2002/25. http://www.hse.gov.uk/research/hsl_pdf/2002/hs10 2-25.pdf

3. Simon, S.I. and M. Leik, 1999. Breaking the safety barrier: Implementing culture change. Profession. Safe., 44: 20-25. http://www.highbeam.com/doc/1P3-39756922.html

4. Fuller, C.W. and F.H. Vassie, 2001. Benchmarking the safety climates of employees and contractors working within a partnership arrangement a case study in the offshore oil industry. Benchmark. Int. J., 8: 413-430. DOI: 10.1108/EUM0000000006386

5. Wiegmann, D.A., T.L.V. Thaden and A.M. Gibbons, 2007. A review of safety culture theory and its potential application to traffic safety. http://www.aaafoundation.org/pdf/WiegmannVonT hadenGibbons.pdf

6. Cooper, M.D., 2000. Towards a model of safety culture. Safe. Sci., 36: 111-136. http://www.behavioural-

safety.com/articles/Towards_A_Model_Of_Safety Culture/

7. Clarke, S., 2003. The contemporary workforce implications for organizational safety culture. Personnel Rev., 32: 40-57. DOI: 10.1108/00483480310454718

8. Dingsdag, D., H. Biggs, V.L. Sheahan and D.J. Cipolla, 2006. A construction safety competency framework: Improving $\mathrm{OH}$ and $\mathrm{S}$ performance by creating and maintaining a safety culture. Cooperative Research Centre for Construction Innovation. Research report. http://eprints.qut.edu.au/5316/
9. Harvey, J., G. Erdos, H. Bolam, M.A.A. Cox, J.N.P. Kennedy and D.T. Gregory, 2002. An analysis of safety culture attitudes in a highly regulated environment. Work Stress, 16: 18-36. http://cat.inist.fr/?aModele $=$ afficheN\&cpsidt $=13562522$

10. Parker, D., M. Lawrie and P. Hudson, 2006. A framework for understanding the development of organizational safety culture. Safe. Sci., 44: 551-562. http://cat.inist.fr/?aModele $=$ afficheN\&cpsidt $=17812871$

11. Wiegmann, D.A., T.L.V. Thaden, A.A. Mitchel, G. Sharma and H. Zhang, 2003. Development and initial validation of a safety culture survey for commercial aviation. Technical Report, University of Illinois AHFD-03-3/FAA-03-1. http://jobfunctions.bnet.com/abstract.aspx?docid=1 78934

12. Cox, S.J. and A.J.T. Cheyne, 2000. Assessing safety culture in offshore environments. Safe. Sci., 34: 111-129.

http://cat.inist.fr/?aModele $=$ afficheN\&cpsidt $=1401450$

13. Flin, R., K. Mearns, P. O'Connor and R. Bryden, 2000. Measuring safety climate: Identifying the common features. Safe. Sci., 34: 177-192. http://cat.inist.fr/?aModele $=$ afficheN\&cpsidt $=1400$ 788

14. Vecchio-Sadus, A.M. and S. Griffiths, 2004. Marketing strategies for enhancing safety culture. Safe. Sci., 42: 601-619. DOI: 10.1016/j.ssci.2003.11.001

15. Grote, G. and C. Kunzler, 2000. Diagnosis of safety culture in safety management audits. Safe. Sci., 34: 131-150. http://cat.inist.fr/?aModele $=$ afficheN\&cpsidt $=1401084$

16. Guldenmund, F.W., 2000. The nature of safety culture: A review of theory and research. Safe. Sci., 34: 215-257. http://cat.inist.fr/?aModele $=$ afficheN\&cpsidt $=1400$ 802

17. Hamaideh, S.H., 2004. Safety culture instrument: A psychometric evaluation. Ph.D thesis, University of Cincinnati.

http://drc.ohiolink.edu/handle/2374.OX/11805?sho $\mathrm{w}=$ full

18. Hsu, S.H., C.C. Lee, M.C. Wu and K. Takano, 2008. A cross-cultural study of organizational factors on safety: Japanese vs Taiwanese oil refinery plants. Accid. Anal. Prev., 40: 24-34. http://www.ncbi.nlm.nih.gov/pubmed/18215529

19. Lawrie, M., D. Parker and P. Hudson, 2006. Investigating employee perceptions of a framework of safety culture maturity. Safe. Sci., 44: 259-276. http://cat.inist.fr/?aModele $=$ afficheN\&cpsidt $=1758$ 3883 
20. O'Dea, A. and R. Flin, 2001. Site managers and safety leadership in the offshore oil and gas industry. Safe. Sci., 37: 39-57. http://cat.inist.fr/?aModele $=$ afficheN\&cpsidt $=9085$ 20

21. Lee, T., 1998. Assessment of safety culture at a nuclear reprocessing plant. Work Stress, 12: 217-237.

22. Yule, R.F.S., 2004. Leadership for safety: Industrial experience. Q. Safe. Health Care, 13: 45-51. DOI: 10.1136/qshc.2003.009555

23. Short, J., L. Boyle, S. Shackelford, B. Inderbitzen and G. Bergoffen, 2007. Commercial truck and bus safety synthesis program: The role of safety culture in preventing commercial motor vehicle crashes a synthesis of safety practice. Transportation Research Board of the National Academies, Washington, Project MC-14. http://www.trb.org/news/blurb_detail.asp?ID=7919

24. Macdonald, B., 2006. Safety culture and leadership.

http://www.ccohs.ca/scholarship/winners/200607/Essay_B_Macdonald.pdf

25. Perezgonzalez, J.D., 2005. Construction Safety Management, a Systems Approach. Lulu, Inc. USA., ISBN: 1411631234, pp: 304.

26. Fernandez-Muniz, B., J .M. Montes-Peon and C.J. Vazquez-Ordas, 2007. Safety management system: Development and validation of a multidimensional scale. J. Loss Prev. Process Ind., 20: $52-68$.

http://cat.inist.fr/?aModele $=$ afficheN\&cpsidt $=1840$ 7760

27. Carrillo, R.A.S., 1998. Expanding managers' leadership role in safety. Profession. Safe., 43: 3841. http://www.actswr.org/c/downloads/NIMS200/NIMS_200_unit_2.ppt
28. Arboleda, A., P.C. Morrow, M.C. Crum, and M.C. Shelley 11, 2003. Management practices as antecedents of safety culture within the Trucking industry: Similarities and differences by hierarchical level. J. Safe. Res., 34: 189-197. DOI: 10.1016/S00224375(02)00071-3

29. Gibbons, A.M., T.L.V. Thaden and D.A. Wiegmann, 2004. Exploration of the correlation structure of a survey for evaluating airline safety culture. Technical Report, University of Illinois AHFD-0406/FAA-04-3.

http://www.humanfactors.illinois.edu/Reports\&Pap ersPDFs/TechReport/04-06.pdf

30. Human Engineering Shore House, 2005. A review of safety culture and safety climate literature for the development of the safety culture inspection toolkit. Health and Safety Executive, Research report 367. http://www.hse.gov.uk/research/rrhtm/rr367.htm

31. Mohamed,S., 2003. Adaptation of the balanced scorecard to measure organizational safety culture. J.Construct. Res., 4: 45-57. DOI: $10.1142 / \mathrm{S} 1609945103000285$

32. Kao, C.S., Y.M. Chung, W.H. Lai and T.F. Chuang, 2007. Analysis of safety culture and safety performance relationship of a major petrochemical corporation in Taiwan. Proceeding of the Symposium on Mary Kay O'Connor Process Safety Center, May 6-6, Mary Kay O’Connor Process Safety Center, Taxes USA., pp: 1-22. http://d.wanfangdata.com.cn/NSTLHY_NSTL_HY 16026430.aspx

33. Kinner, P.R. and C.D. Gray, 2007. SPSS 15 Made Simple. 1st Edn., Psychology Press, New York, ISBN: 10: 1841696862, pp: 640. 